\title{
$\mathrm{BIM}$ 데이터를 적용한 증강현실 기반의 건설관리시스템 개발에 관한 연구
}

\author{
안지연 ${ }^{1}$, 최정민 ${ }^{1}$, 권순호 $^{1}$, 송두형 ${ }^{2}$, 옥종호 ${ }^{1^{*}}$ \\ ${ }^{1}$ 서울산업대학교 대학원, ${ }^{2}$ 메타이오아시아
}

\section{A Study on the Development of the Project Management System based on Augmented Reality}

\author{
Ji-Yean An ${ }^{1}$, Jeong-Min Choi ${ }^{1}$, Soon-Ho Kwon ${ }^{1}$, Doo-Hyung Song ${ }^{2}$ \\ and Jong-Ho Ock ${ }^{1^{*}}$ \\ ${ }^{1}$ Department of Architectural Engineering, Seoul National University of Technology \\ ${ }^{2}$ MetaioAsia
}

\begin{abstract}
요 약 최근 $3 \mathrm{D}$ 파라메트릭 모델링 기법의 발달에 힘입어 비정형 건축 프로젝트가 증가하고 있다. 기존의 $\mathrm{BIM}$ 시뮬 레이션 의사결정 지원시스템은 가상현실에서 구현되기 때문에 효율적이지 못했다. 이에 본 연구에서 효율적 의사결정 지원을 위한 증강현실 기반 시뮬레이션 시스템인 "AR naviX"를 개발하였다. 이 시뮬레이션 시스템은 현장사진과 동 영상자료 혹은 레이져 스캐닝 데이터를 활용하여 사용자가 보다 높은 현실감과 몰입감을 느낄 수 있도록 함으로써, 의사결정에 소비되는 시간을 단축시킨다.
\end{abstract}

\begin{abstract}
The number of Free-Form construction projects are increased by development of 3D parametric modeling technology. The reason of Free-Form Architecture's appearance is advance of digital technology. BIM simulation decision making support is inefficient because it is used in virtual reality. In this study, we developed "AR naviX" which is the digital contents of construction management based on AR for effective decision making support to Free-Form construction project. It reflects construction site by using site picture and video, or Laser scanning data. User feel high reality and is absorbed in augmented reality. So they can reduce the time of decision.
\end{abstract}

Key Words : Augmented Reality, BIM, Free-form Buildings, Simulation, Decision Analysis

\section{1. 서론}

건설 사업이 대형화, 복잡화됨에 따라 프로젝트의 각 단계별로 발생되는 방대한 정보량을 효율적으로 관리하 기 위한 각종 기술들이 개발되고 있다. 다양한 건설데이 터들의 정보화 단계 측면에서 보면 $2 \mathrm{D} \mathrm{CAD}$ 에서 $3 \mathrm{D}$ $\mathrm{CAD}$ 로, 그리고 최근에는 건물 전 생애주기의 정보를 통 합하고자 하는 Building Information Modeling (BIM) 환 경으로 빠른 전환이 이루어지고 있다.
$\mathrm{BIM}$ 기술은 파라메트릭 모델링기술을 활용하여 건설 프로젝트의 설계단계와 시공단계 동안 발생하는 다양한 3 차원 형상정보와 속성정보를 연계관리하고 가공할 수 있는 환경을 제공함으로써 건설프로젝트의 팀워크를 증 진하고 설계 및 시공 품질향상, 공기단축, 수익성 향상 등 의 효과를 제공하는 것으로 분석된다.

또한 BIM 기술은 도면자동생성, 물량산출, 공정관리, 공정 간 간섭검토, 물량산출 등의 기능을 제공할 뿐 만 아니라 건설의 설계, 시공단계에서 다양한 시뮬레이션을

본 논문은 서울시 산학연 협력사업(과제번호:ST090846)에 의해 수행되었음.

*교신저자 : 옥종호(ockjh@snut.ac.kr)

접수일 10년 06월 03일 수정일 (1차 10년 07월 14일, 2차 10년 07월 29일)

게재확정일 10 년 08 월 10 일 
가능하게 함에 따라 "지능적인 건축시물레이션 (an intelligent simulation of architecture)" 이라고 정의되기도 한다. 최근 건설프로젝트의 기획, 설계, 시공, 유지관리 단계 간의 효율적인 의사소통과 프로젝트 성과의 일관성 을 위해 다양한 BIM 기술 기반의 시뮬레이션 도구들이 개발되고 있지만, 다음과 같은 한계를 나타내고 있다.

첫째, 시뮬레이션 환경에 관한 사항으로서, 현행 시뮬 레이션 시스템들은 가상공간에 한정되어 구현된다. 건설 프로젝트 현장 여건은 수시로 변하기 때문에 건설프로젝 트 관계자 간 많은 정보교환을 필요로 한다. 현실정보와 가상정보를 철저히 분리하는 현행 시뮬레이션 시스템은 의사결정 커뮤니케이션에 지연을 발생시킨다.

둘째, 의사결정 지원도구로써의 활용성에 문제가 있 다. 건설프로젝트는 설계단계에서 시공단계로 진행함에 따라 가시적인 기성물이 출현하게 되며 기성물과 추후 건축하여야 하는 건설 간의 신속한 검토가 필요하다. 그 러나 현행 시뮬레이션의 경우 현장에서 발생하는 정보를 수작업으로 일일이 재모델링하는 등의 부가적인 작업을 필요로 하기 때문에 프로젝트관리자의 업무추진에 지연 과 추가비용을 발생시킨다.[1]

시뮬레이션은 모델을 활용하여 모의실험을 하기 때문 에 실질적인 상황과 가상의 상황을 연계하여 수정 또는 보완하여야 한다. 그러나 모델의 구조가 결과에 많은 영 향을 미치기 때문에 부정확한 데이터가 입력되었을 경우 왜곡된 결과가 도출될 수 있으며 모델작성자에 따라 결 과에 많은 차이가 발생할 수 있다.

본 연구는 이러한 문제점을 보완하면서 건설관리자의 업무를 효율적으로 지원할 수 있는 도구개발을 위해 건 설현장의 실제정보에 바탕을 둔 증강현실 (Augmented Reality, 이하 AR)기반의 건설시뮬레이션시스템을 개발 하는 것을 목적으로 한다. 이를 위해 BIM 기법을 활용하 여 설계되고 최근 시공이 완료된 주택 건축물을 대상으 로 $\mathrm{AR}$ 환경에서 설계단계, 시공단계, 유지관리단계의 시 뮬레이션이 구동되는 시스템 (Augmented Reality Navigator, 이하 AR naviX) 을 구축하였으며 AR과 BIM 관련 전문가 워크샵을 실시하여 향후 보다 발전적인 $\mathrm{AR}$ 시스템 구현 시 반영할 수 있는 방법론과 개발된 시스템 의 적절성, 한계점, 향후 연구방향을 도출하였다.

\section{2. 관련연구}

\subsection{AR의 예비적 고찰}

$\mathrm{AR}$ 은 현실세계에 대한 유용한 정보 제공을 목적으로
현실세계와 가상의 데이터를 실시간으로 혼합하는 기술 이다. VR (Virtual Reality)이 가상의 콘텐츠로만 구성되 는 것에 비해 $\mathrm{AR}$ 은 그림 1 과 같이 현실세계와 가상의 콘 텐츠를 혼합시키기 때문에 보다 높은 현실감을 줄 수 있 다는 장점이 있다.[2]

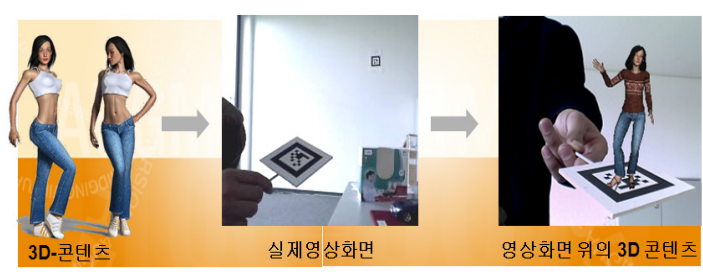

[그림 1] 증강현실

$\mathrm{AR}$ 은 디스플레이(Display), 카메라(Camera), 마커(Marker), AR Software로 구성된다. 디스플레이는 현실정보와 가상 정보가 중첩된 영상을 보여주는 장비로 $\mathrm{HMD}$ (Head Mounted Display) 장비가 대표적이다. 현실정보는 카메 라를 통해 획득되는 실제 영상이며, 가상정보는 $\mathrm{AR}$ 환경 에서 구현 가능한 파일형식으로 변환된 3D 모델이다. 이 가상정보는 마커를 통해 현실정보에 중첩되며 현실정보 를 구축하는 카메라의 성능에 따라 마커의 인식거리가 제한된다. 그리고 $\mathrm{AR}$ 구현을 위한 솔루션 프로그램인 $\mathrm{AR}$ software를 통해 마커 이미지 추출, 구현위치 추적, 정합의 과정을 거쳐 계산된 위치에 $3 \mathrm{D}$ 객체를 중첩함으 로써 $\mathrm{AR}$ 이 구현된다.

\section{2 건설 산업의 $\mathrm{AR}$ 적용 연구}

증강현실은 다양한 산업분야에서 연구·활용되고 있다. 자동차 공장의 부품조립 매뉴얼이나 교육용 가상화단, 증 강현실 애완동물 사육 프로그램, 화장 및 헤어 변경예측 프로그램 등 이미 상용화된 사례도 쉽게 찾을 수 있다. 특히 최근 들어 가상정보 입력방식이 마커에서 GPS로 변 화됨과 동시에 스마트폰 (PC 기능을 갖춘 휴대전화)의 확산에 힘입어 증강현실을 활용한 서비스가 급증하고 있 다. 건설 산업에서도 2000 년대 들어 $\mathrm{AR}$ 의 잠재성에 주목 하기 시작했지만 타 산업에 비해 아직은 관련된 연구들 이 초기단계에 머물러 있는 실정이다.

박소영(2007)이 수행한 연구에서는 건물 구성요소를 크게 물리적 요소, 사용/관리요소로 나누고 이것을 XML 기반의 통합데이터베이스 DTD설계로 구축한 후, $3 \mathrm{D}$ 데 이터모델을 작성하여 다중마커인식이 가능한 건물 유지 관리시스템을 개발하였다.[3]

임줌폰(2006)은 $2 \mathrm{D}$ 를 기반으로 작성된 $3 \mathrm{D}$ 형태의 
VRML 데이터 모델을 마커 인식을 통해 불러들여 환경 적 분석·관리가 가능한 $\mathrm{AR}$ 프로토타입 시스템을 개발하 였다. 시스템은 다양한 모듈(위치추적 모듈, $\mathrm{AR}$ 시각화 모듈, 4D CAD모듈, 일조 분석 모듈, 조망 분석 모듈, 3D 유틸리티 모듈)로 구성되었으며, 현실정보의 위치와 방향 추적을 위해 GIS엔진을 활용하였다.[4]

정성수(2009)는 $\mathrm{AR}$ 에서 3D 데이터를 불러오기 위해 사용하는 마커가 카메라나 현장의 상황에 따라 인식 편 차가 크다는 점에 주목하여 무타깃 기법을 도입하였다. 이 기법은 영상에서 창틀이나 건물 외곽과 같은 외부표 정요소의 3 차원 좌표를 추출하여 데이터 모델의 특정점 과 일치시키는 방식의 모니터링 기법이다.[5]

해외 $\mathrm{AR}$ 관련 연구를 살펴보면 건축설계단계에 $\mathrm{AR}$ 을 접목시키기 위한 $\mathrm{AR}$ 디자인 환경에 대한 연구[6], $\mathrm{AR}$ 기 반 의사결정지원시스템 개발을 위한 기술적 분석에 대한 연구[7], $\mathrm{AR}$ 을 활용하여 일본 전통건축의 디지털 콘텐츠 를 개발한 연구[8], 건설대지조성 공정에 $\mathrm{AR}$ 접목을 위 한 연구[9], $\mathrm{AR}$ 을 건축설계, 도시계획, 구조계획 등의 교 육에 활용하기 위한 실험적 연구[10] 등이 수행되었다.

살펴 본 바와 같이 건설산업에서 $\mathrm{AR}$ 을 적용한 연구 는 현실정보의 취득, 마커(Marker) 인식 방식, $3 \mathrm{D}$ 모델 정합 방식 등과 같이 $\mathrm{AR}$ 구현을 위한 기술적인 부분이 주를 이루고 있는 것으로 분석되었다. 또한 프로토타입 적용에 있어서 설계, 유지관리 분야에 집중되고 있으며 본 연구가 시도하는 바와 같이 설계, 시공, 유지관리 단계 에서 적용할 수 있는 시스템 개발은 이제 연구초기단계 인 것으로 분석되었다.

\section{$2.3 \mathrm{BIM}$ 데이터의 활용에 관한 연구}

$\mathrm{BIM}$ 관련 연구는 그동안 주로 $\mathrm{BIM}$ 의 활용사례를 중 심으로 건설정보의 공유 및 교환성을 확인하는 논문이 많았는데 이는 건설 산업의 특성 상 하나의 프로젝트에 다수의 이해관계자가 참여하기 때문에 건설프로젝트의 효율성 측면에서 건설정보화가 필요하기 때문인 것으로 분석된다. 최근에는 표1에서 보는 바와 같이 개방형 BIM 의 도입을 위한 가이드라인 개발, $\mathrm{IFC}$ 를 활용한 $3 \mathrm{D}$ 상용 $\mathrm{CAD}$ 간의 데이터 호환성 분석, 공정원가통합관리시스템 등에 관한 연구가 수행되고 있다.

\section{4 관련연구 분석결과}

$\mathrm{AR}$ 적용 연구에서는 건설산업에 적용 가능한 다양한 프로토타입 시스템 개발이 시도되고 있으나, 건설 프로젝 트 전 단계에 걸친 통합시스템으로의 연구가 부족한 것 으로 분석되었다. 또한 BIM데이터 활용 연구의 경우,
$\mathrm{BIM}$ 데이터 간 호환에 관한 연구가 대부분이며 그 안의 속성정보를 실제 건설프로젝트에 적용하기 위해 방향을 제시하지는 못한 것으로 분석되었다.

이에 본 논문에서는 $\mathrm{BIM}$ 기반 건설관리 통합시스템을 구축하여 $\mathrm{AR}$ 환경에서 구현함으로써 현장여건을 효율적 으로 반영할 수 있는 도구를 개발하고자 한다.

[표 1] BIM 데이터 활용에 관한 연구

\begin{tabular}{|c|c|}
\hline 저자 & 내용 \\
\hline $\begin{array}{l}\text { 정도영 } \\
\text { 외[11] }\end{array}$ & $\begin{array}{l}\text { - 3D BIM모델을 기반으로 비용/일정프로그램으로 } \\
\text { 데이터 Export를 통해 통합관리 방안제시 } \\
\text { - 3D 모델과 관련된 구조물 구성요소 분류체계(EBS: } \\
\text { Element Breakdown Structure)를 시설물, 공간, 부 } \\
\text { 위, 공종으로 분류 } \\
\text { - Autodesk Revit Architecture를 이용하여 3D 대상 } \\
\text { 구조물 3D 모델링 } \\
\text { - EVMS시스템을 통해 작성된 비용정보, 일정정보 } \\
\text { 를 Autodesk Navisworks를 통해 BIM 모델과 연 } \\
\text { 결 }\end{array}$ \\
\hline $\begin{array}{l}\text { 김지원 } \\
\text { 외[12] }\end{array}$ & $\begin{array}{l}\text { - 다양한 BIM 어플리케이션으로 작성된 동일한 건 } \\
\text { 물모델의 건축, 구조부분을 대상으로 호환성 비 } \\
\text { 교·검증 } \\
\text { BTA, ARC, RVT의 데이터저장 방식 및 } \\
\text { Open/Save 방식을 확인하여 IFC포맷으로의 } \\
\text { Import/Export 가능 확인 } \\
\text { - 각 어플리케이션에서 추출된 *.ifc 파일을 원본파 } \\
\text { 일 및 타 어플리케이션 파일과 물량정보, 속성정 } \\
\text { 보, 위치정보, 형상정보의 확인을 통해 호환성 비 } \\
\text { 교 }\end{array}$ \\
\hline $\begin{array}{l}\text { 서종철 } \\
\text { 외[13] }\end{array}$ & $\begin{array}{l}\text { - 국내 공공발주에서 BIM 적용을 계획하거나 추진 } \\
\text { 과정에서 가이드가 될 수 있는 요구조건, 고려사 } \\
\text { 항 등의 기본방향을 제시 } \\
\text { - 법·제도 측면 - BIM을 고려한 설계비 산정 및 발 } \\
\text { 주계획 수립, 인증제도 도입, 법제도 규정의 명분 } \\
\text { 화 필요 } \\
\text { - 기술적용 측면 - BIM 적용 대상 업무/범위 선정, } \\
\text { 적용 성과 측정 및 적용 수준 정의 필요 } \\
\text { BIM 표준 로드맵 개발 측면 - 작업프로토콜 및 } \\
\text { 컨텐츠 개발, 데이터 보안 및 소유권 보호에 관한 } \\
\text { 요소기술 도입 등이 필요 }\end{array}$ \\
\hline $\begin{array}{l}\text { 김인한 } \\
\text { 외[14] }\end{array}$ & $\begin{array}{l}\text { - IFC 기반 BIM으로 불리는 개방형BIM(Open } \\
\text { BIM)의 국내 지침 개발을 위한 방향 제시 } \\
\text { - 국외 (미국, 핀란드, 독일, 덴마크)의 지침을 통해 } \\
\text { 로드맵 개발 필요성 확인 } \\
\text {. 다양한 이해당사자들의 협력을 위한 업무 대상, } \\
\text { 범위, 절차, 분야별 BIM 요구조건 등을 포함한 } \\
\text { 지침이 필요 }\end{array}$ \\
\hline $\begin{array}{l}\text { 안승준 } \\
\text { 외[15] }\end{array}$ & $\begin{array}{l}\text { - BIM을 기반으로 객체지향형 공정 모델링을 작성 } \\
\text { 하여 시스템 프로토타입을 구현함으로써 그 효용 } \\
\text { 성을 검증 } \\
\text { - 건설을 이루는 계층 요소 최하위 수준에 해당하는 } \\
\text { 작업요소를 표현하기 위한 작업요소객체 (CTO) } \\
\text { 생성 } \\
\text { 프로젝트 실무의 공정관리 수준에 해당하는 공정 } \\
\text { 을 표현하기 위해 공정객체 (CPO) 생성 } \\
\text { JAVA 환경에서 CTO, CPO로 분류된 BIM 객체 } \\
\text { 를 시공정원가 통합관리 시스템으로 구현 }\end{array}$ \\
\hline
\end{tabular}




\section{AR naviX 시스템 기능정의}

\section{1 시스템 기능 정의}

건축물의 건설 프로세스는 크게 계획, 설계, 시공, 유 지관리 단계로 정의된다. 계획단계에서 건설 프로젝트의 타당성조사가 실시되며 설계단계에서는 이것을 토대로 건물의 규모, 배치, 형태, 개략공사방법 및 기간, 개략 공 사비 등에 관한 조사, 분석, 비교·검토를 거쳐 최적안을 선정한다. 시공단계에서는 공법선정, 자재 및 노무조달을 포함한 비용/공정계획, 안전관리계획에 따라 건물을 구축 한 후 유지관리단계에서 시설사용자의 편의와 시설별 관 리기준에 따라 고정시설과 가구 등의 가변시설을 운영, 유지관리 및 보존하게 된다.

본 연구에서 개발한 $\mathrm{AR}$ naviX는 이러한 건설 각 단계 별로 참여하게 되는 발주자, 설계자, 시공자, 시설관리자 간의 협업적 의사결정을 지원하기 위한 의사결정지원시 스템 (Decision Support System, 이하 DSS) 으로서의 기 능을 가진다. DSS는 의사결정자의 능력을 향상시킬 수 있는 보조역할로서의 컴퓨터 기반 시스템이라고 정의되 며[16] DSS 개발 시 가장 중요한 요소 중 하나는 의사결 정문제의 정확한 정의이다.

$\mathrm{AR}$ naviX가 대상으로 하는 의사결정 업무를 결정하 기 위해 본 연구가 모델링 대상으로 삼고 있는 주택프로 젝트의 건축주 및 설계자와 면담을 실시하여 이 프로젝 트의 각 단계별 주요 의사결정 업무를 조사하였으며 그 림 2 와 같이 시스템에서 구현할 주요업무 및 참여주체를 개념적으로 정리하였다.

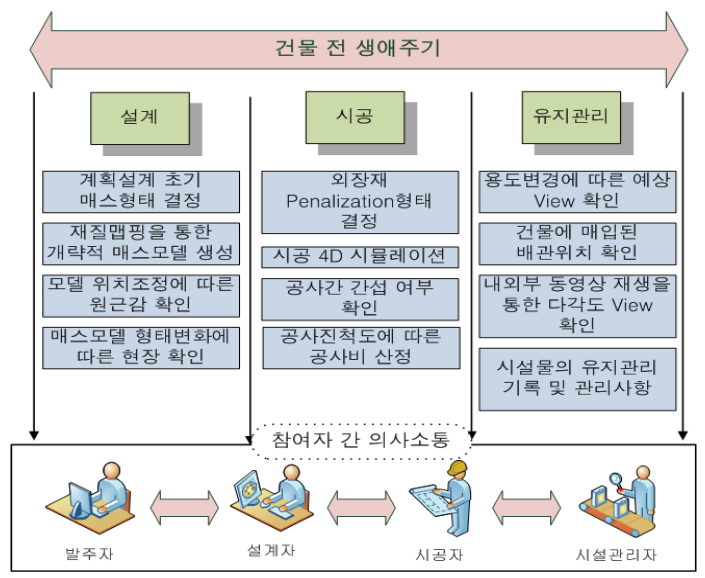

[그림 2] 프로젝트 각 단계별 주요 관심사항

조사된 주요 의사결정 업무를 기반으로 설계단계 시스 템은 계획설계 단계에서 발주자와 설계자의 매스모델 형
태결정을 지원하기 위해 건축대지사진으로 구성된 현실 정보 위에 $\mathrm{BIM}$ 매스모델을 불러들여 건물의 형태와 규 모를 파라메트릭 기법을 활용하여 조정하고 재질 맵핑 조정기능을 통해 재질감을 확인할 수 있도록 구현하였다.

시공단계 시스템에서는 공정진행에 따라 건설된 기성 부분을 사진 또는 레이저 스캐닝 기법을 통하여 현실정 보화하고 향후 건설될 공종의 BIM모델을 이 현실정보와 조합하여 $4 \mathrm{D}$ 공정시뮬레이션과 공종 간 간섭여부 확인이 가능하도록 하였다. 유지관리단계 시스템은 배관 BIM모 델로 매입된 배관의 위치를 확인하고, 인테리어 및 조경 모델 그룹으로 변경된 모습을 확인하는 것을 주요 업무 로 정의하여 구현하였다.

\section{2 구축시스템 구성 및 구축환경}

건설의 각 프로세스와 시스템 요구기능 분석을 기반으 로 시스템을 구축하였으며 시스템 구성은 아래 그림 3과 같다.

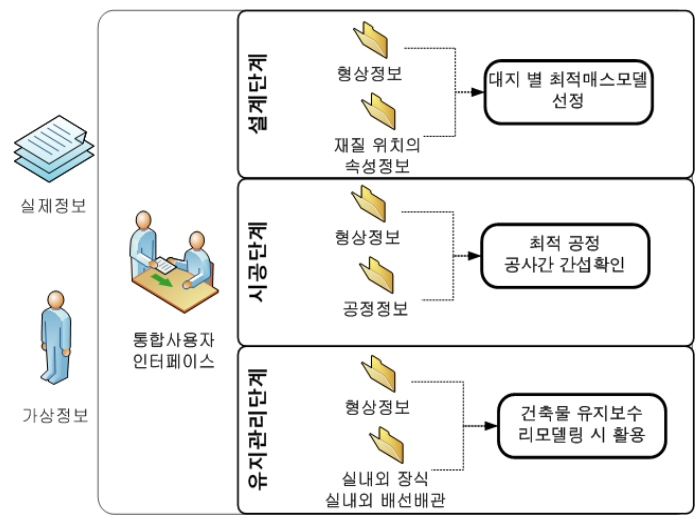

[그림 3] 시스템 구성도

시스템을 구성하는 정보는 크게 가상정보와 현실정 보로 나뉘며 설계단계, 시공단계, 유지관리단계 시스템은 사용자통합 인터페이스를 통해 다수의 참여자가 동일한 인터페이스로 조작이 가능하도록 한다. 데이터의 경우 현 실정보는 Marker가 입력된 현장 영상, 사진, 레이저 스캐 닝을 통해 As-Built 된 데이터이며, 가상정보는 증강현실 에서 구현 가능한 $3 \mathrm{D} \mathrm{BIM}$ 모델로 구성되었다. 증강현실 데이터의 원활한 활용과 타 증강현실데이터의 호환성을 향상시키기 위해 시스템 구현에 사용된 모든 소프트웨어 는 표준화된 상용도구의 사용을 원칙으로 하였다.

$\mathrm{AR}$ naviX는 Window $\mathrm{XP} / \mathrm{VISTA}$ 운영체제에서 구동 가능하며, ‘net Framework 3.0 기반의 C\#언어'를 사용하 여 구현하였다. 시스템 상의 $\mathrm{AR}$ 구현을 위한 $\mathrm{AR}$ 
Software로는 독일의 증강현실 전문개발회사인 metaio사 의 Unifeye SDK(Software Development Kit)을 활용하였 다.

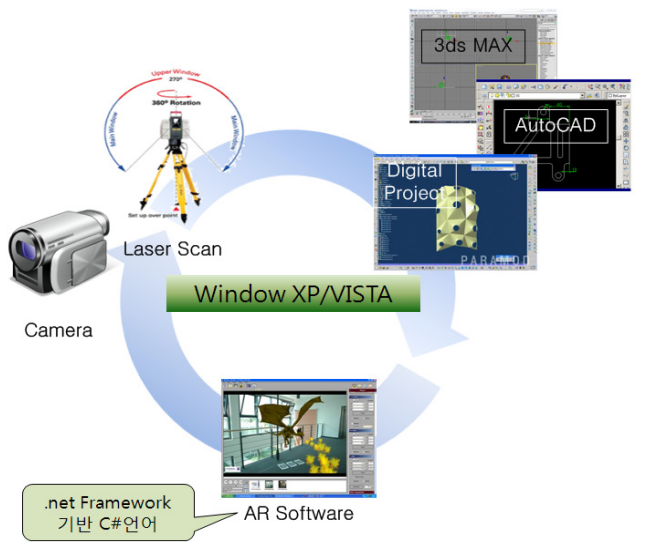

[그림 4] 구현도구 및 환경

\section{4. 시스템 설계 및 구현}

\section{1 시스템 구축을 위한 사전작업}

본 연구는 수도권에 소재한 비정형 주거용 건축물 그 림 5을 대상으로 프로토타입 시스템을 개발하였다. 이 건 물은 지상 2 층에 연면적 $418.2 \mathrm{~m}^{2}$ 의 소규모 주택 건물로서 철골조 뼈대에 외장을 GFRC 패널로 마감하였다.

시스템 구축에 앞서 시스템에서 활용할 데이터를 정리 하여 $\mathrm{AR}$ 환경 구현을 위한 사전작업이 필요하였다. 선행 되어야 할 작업은 $\mathrm{BIM}$ 증강현실 데이터 구축, 마커 좌표 값 추출, 재질정보 입력을 위한 속성영역 구성이다.

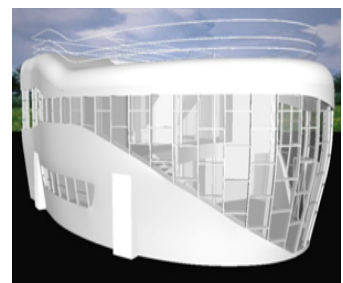

3D 설계 모델

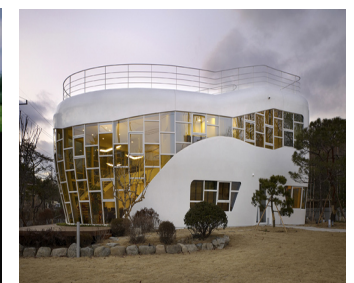

완공 모습
[그림 5] 수도권 소재 비정형건축물

먼저 $\mathrm{BIM}$ 증강현실 데이터 구축을 위해 $2 \mathrm{D}$ 기반의 $\operatorname{AutoCAD}(* . \mathrm{dwg})$ 파일로 구축되어 있는 평면도, 입·단면 도를 활용하여 $3 \mathrm{D}$ 형태의 구조 프레임을 구축하여 부재
의 좌표점을 추출하였다. 구축된 $3 \mathrm{D}$ AutoCAD 모델정보 를 바탕으로 비정형 건축물 BIM 도구인 Digital Project를 활용하여 구조체의 메인 프레임을 BIM모델로 구축하였 다. $\mathrm{BIM}$ 모델은 $\mathrm{AR}$ 환경으로 불러들일 수 있는 형식의 데이터로 변환 과정이 필요하며, $3 \mathrm{D}$ 어플리케이션의 Export 기능을 통해 VRML 포맷으로 변환하여 최종 $\mathrm{AR}$ 환경 모델을 완성하였다[그림 6].

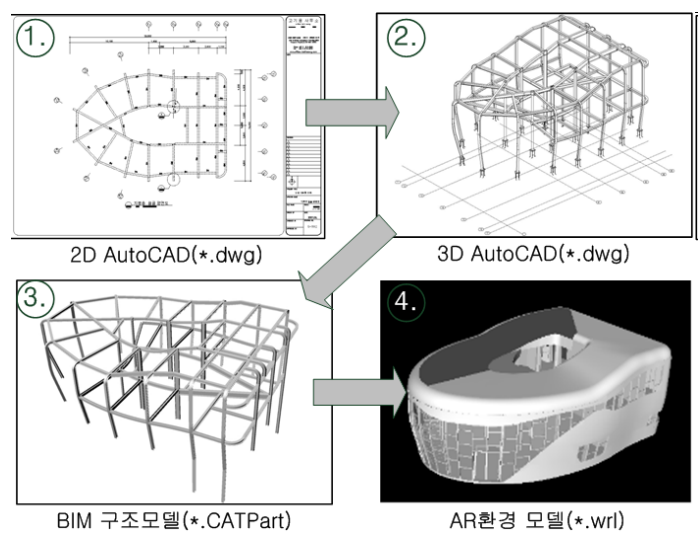

[그림 6] $\mathrm{BIM}$ 증강현실데이터 구축

완성된 $\mathrm{AR}$ 모델은 실제정보 속의 마커 좌표에 전확히 중첩되어야 하기 때문에 시스템 개발에 앞서 마커를 생 성하고 좌표값을 추출했다. 시스템에서 사용가능한 마커 의 개수는 최대 10 개까지이며 마커는 현실정보 안에 포 함되어 고유의 좌표값을 지정받게 된다. 이 좌표를 추출 하는 방법을 Tracking이라고 하며 아래 그림 7은 마커의 좌표를 추출하여 XML 형식으로 Tracking 된 데이터의 일부를 나타낸다.

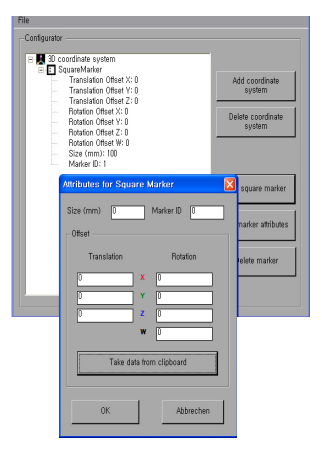

Marker 정보입력

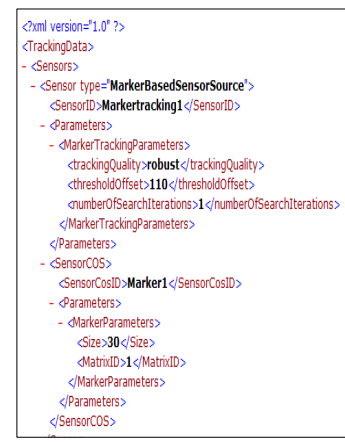

Tracking된 XML데이터 일부
[그림 7] Marker생성 및 좌표점 추출 


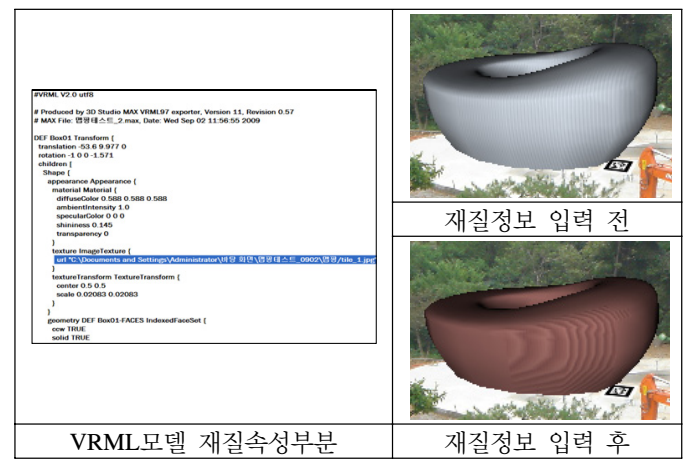

[그림 8] VRML모델 재질속성 변경

마지막으로 설계단계에서 활용되는 매스모델에 재질 정보를 입력하기 위해 BIM 모델을 3ds MAX로 불러들여 VRML 파일로 추출함으로써 재질정보가 입력 가능한 속 성영역을 구성하였다. 이 속성영역에 재질의 이미지를 입 력한 후 저장을 하게 되면 그림 8 에서 보여주는 바와 같 이 VRML 모델에 재질이 적용된 것을 확인할 수 있다.

이로써 시스템 구축을 위한 사전작업을 마치고, 요구 기능 분석을 통한 시스템 기능과 인터페이스를 구축하였다.

\section{2 설계단계 시스템 구축}

각 단계별 시스템에 구현한 요구기능은 프로세스 흐름 을 활동(Activity) 단위로 모델링하는 방법인 IDEF0 방법 을 활용하여 분석하였다. IDEF0는 정보시스템 구축을 위 해 프로세스, 요구정보 등을 논리적, 물리적으로 분석·설 계하는 방법인 IDEF 기법 중 하나로 기능분석에 중점을 둔 방법이다. IDEF0 모델은 활동(Activity)과 ICOM(Input, Control, Output, Mechanism)으로 구성되며 각 단계별 시 스템의 활동을 중심으로 필요정보와 참여자, 제어정보 등 을 다이어그램으로 작성해 요구기능을 도출하였다.

설계단계 시스템은 초기 매스설계 단계의 의사결정을 지원하기 위한 시스템으로 해당 건물 설계자와 면담을 통해서 요구기능을 분석한 후, 그림 9 와 같이 설계단계 IDEF0 모델을 구성하였다.

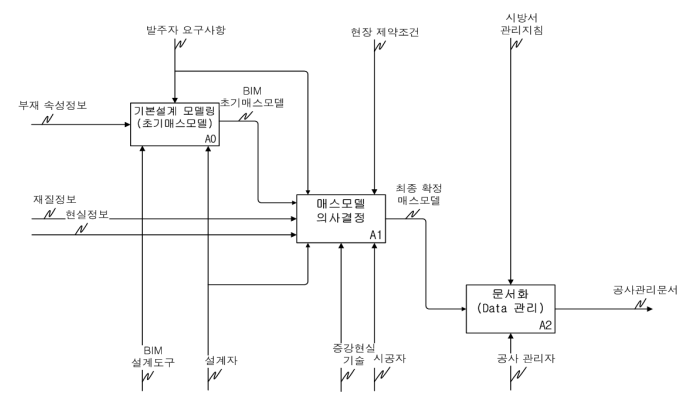

[그림 9] 설계단계 요구기능 분석
IDEF0 모델에 의하면 계획설계 단계에서 건축가가 스 케치, 축소모형 등의 형태로 표현한 매스모델을 디지털화 하여(A0), 방향, 스케일, 재질감 등의 매스모델 의사결정 을 하고(A1), 최종적으로 결정된 사안을 문서화함(A2)으 로써 의사결정이 완료된다. 이 때 요구되는 기능은 (1) $\mathrm{BIM}$ 모델 및 현장정보 $\mathrm{Load} / \mathrm{UnLoad}$, (2)이동/회전/확대· 축소, (3)데이터 저장, (4)재질맵핑이며, (1),(2),(3)번 기능은 각 단계별 시스템에 공통적으로 요구되므로 같은 위치에 인터페이스를 구성하였다. 그림 10 은 설계단계 시스템 화면을 나타낸다.

이를 통해 설계자는 실제 현장에 가지 않고도 최적의 건물 배치 및 형태결정을 할 수 있게 된다. 또한 시스템 을 사용하는 관련 담당자들은 시스템 오른쪽 상단의 Tutorial 메뉴를 통해 시스템 활용법을 익혀 쉽게 시스템 조작이 가능하도록 구성하였다.

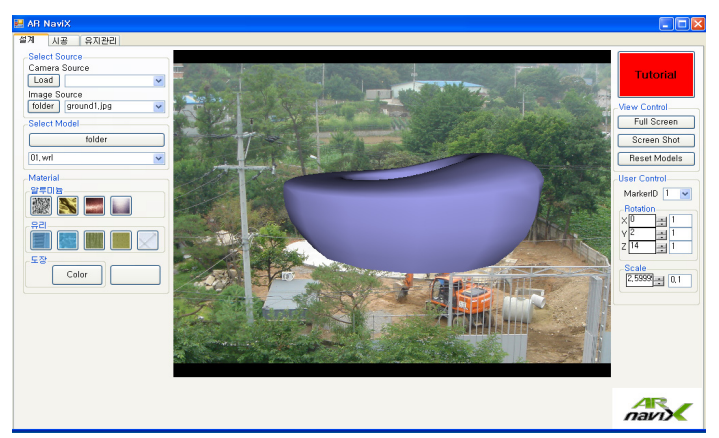

[그림 10] 설계단계 시스템 화면

\section{3 시공단계 시스템 구축}

시공단계는 공정 및 간섭검토를 지원하기 위한 시스템 으로 아래 그림 11 은 시공단계 시스템 기능 정의를 위해 활용한 IEDF0 모델이다.

본 연구에서 활용한 대상 건축물은 비정형 건축물로 일반적인 정형 건축물보다 복잡한 디자인의 외피를 시공 하는 데 많은 어려움이 있게 된다. 외피를 원활히 시공하 기 위해서는 건물외장재를 공장제작 및 현장시공 가능한 여러 부분으로 나누는 Panelization을 수행하게 되며 이 방식에 따라 공기 및 공사비에 차이가 발생한다. 따라서 IDEF0 방법으로 기능 정의를 분석할 때, Panelization을 시작으로 모델화를 진행해 나갔다.

사용자 요구기능 분석을 통해 시공단계 시스템에 $4 \mathrm{D}$ 시뮬레이션 기능을 정의하였다. 1단계로 재질 선택을 한 후, 다음 단계로 Panelization 타입을 선택(A0)한다. 선택 된 타입에 따른 외피 형상을 확인할 수 있으며, 이를 각 각 공정 시뮬레이션에 적용할 수 있다. 


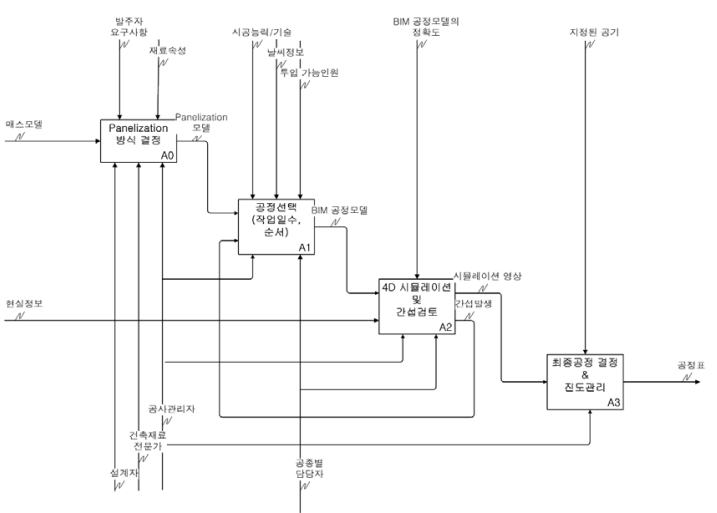

[그림 11] 시공단계 요구기능 분석

각 공정은 step 9 까지 정의되어 있으며 시공자, 공종별 담당자 및 발주자와의 의사소통을 통해 그림 12 와 같이 적절한 공정순서와 기간을 정하게 된다(A1). 이렇게 정의 된 공정모델은 4D play를 통해 시뮬레이션(A2) 할 수 있 다. 시뮬레이션 도중 간섭체크 기능으로 공종별 간섭여부 를 확인하여 결과적으로 참여자들 오류에 대한 Feed-back 시간을 단축시켜 준다.

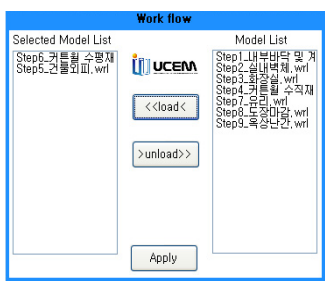

기간 조정

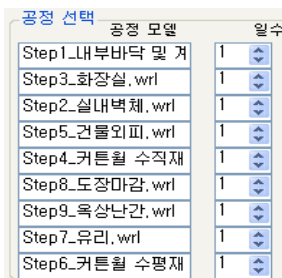

공정순서 조정
[그림 12] 4D시뮬레이션 기능

그림 13은 시공단계 시스템 화면을 보여준다. 시공단 계 시스템은 골조의 시공사진을 바로 적용하므로 변화 하는 현장상황을 따로 모델링할 필요가 없으며, 비정형 골조형태에 따른 외장재의 변화된 모습을 실제 공사사진 위에 실시간으로 확인이 가능하다. 또한 외장재의 재료에 따른 재질감의 변화와 panelization에 따른 외관의 형태를 실시간 확인으로 곡면형태별, 재료, panelization 형태별 로 $4 \mathrm{D}$ 시나리오 구성이 가능하고 현장사진위에 시뮬레이 션 구현이 가능하다.

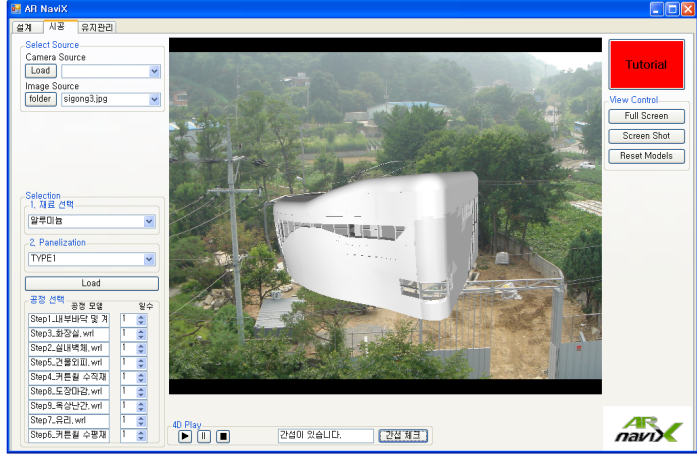

[그림 13] 시공단계 시스템 화면

\section{4 유지관리단계 시스템 구축}

유지관리 단계 시스템은 건물 수선 및 변경과 시설물 관리를 위한 시스템으로 (1)실내인테리어 변경, (2)외부 조 경 변경, (3)배관설비 확인의 세 가지 요소로 구성하였다. 요구기능 분석은 모든 구성 요소를 포함하는 포괄적인 모델화를 통해 단일 시스템에 모든 요구기능이 정의될 수 있도록 하였다. 그림 14는 유지관리단계 시스템 요구 기능 분석을 위한 IDEF0 모델이다.

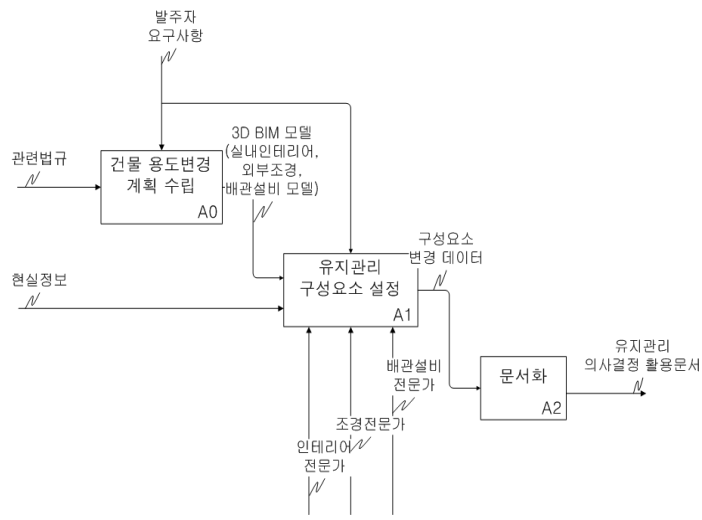

[그림 14] 유지관리단계 요구기능 분석

요구기능을 분석한 결과, 유지관리단계 시스템에서는 시설유지관리를 위한 설비시스템 확인, 용도변경 시 변경 후 예상모습 확인, 건물 사용연수에 따른 내·외관 노후화 정도 측정 등의 기능이 요구되었다. 이 중 배관설비 확인 및 용도변경 후 예상모습 확인에 대한 요구기능을 구현 하였다. 이에 따라 구성요소별로 별도의 $3 \mathrm{D}$ 증강현실 모 델그룹이 필요한 것으로 분석되었다. 이에 따라 시스템 모델 $\mathrm{Load}$ 기능에 세 종류의 3D 모델그룹을 구성하였다. 이 외에 참여자 간 커뮤니케이션을 통해 모델의 추가가 필요할 경우, 증강현실 파일포맷(*.wrl)을 가진 어떠한 모 
델도 추가할 수 있도록 하였다. 아래 그림 15 는 유지관리 시스템 화면을 나타낸 것이다.

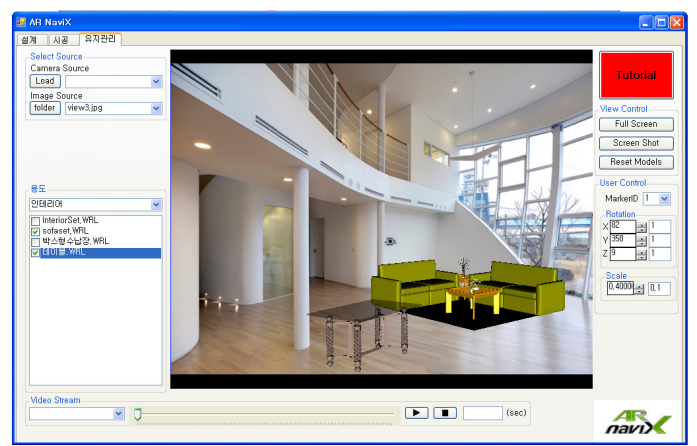

[그림 15] 유지관리단계 시스템 화면

앞선 두 시스템과는 달리 유지관리 단계에서는 레이져 스캐닝 데이터를 활용하여 외부 조경 모델을 어느 방향 에서나 시뮬레이션으로 볼 수 있도록 하여 의사결정을 위한 참여자 커뮤니케이션을 원활하게 할 수 있도록 하 였다.

\section{4 통합인터페이스 구축}

본 연구는 건설 프로세스 전 과정에서 활용 가능한 통 합시스템 구축에 목표를 두고 있다. 따라서 앞서 단계별 로 구축된 시스템을 통합인터페이스를 통해 접근할 수 있도록 하여 각 단계별 시스템의 의사결정정보가 상호 유기적으로 활용되도록 하였다.

아래 그림 16 과 같이 통합인터페이스의 텝(Tab)을 통 해 각 단계별 시스템으로 전환이 가능하고, 건설 프로세 스의 순차적 접근 및 독립적 접근이 모두 가능하도록 하 였다.

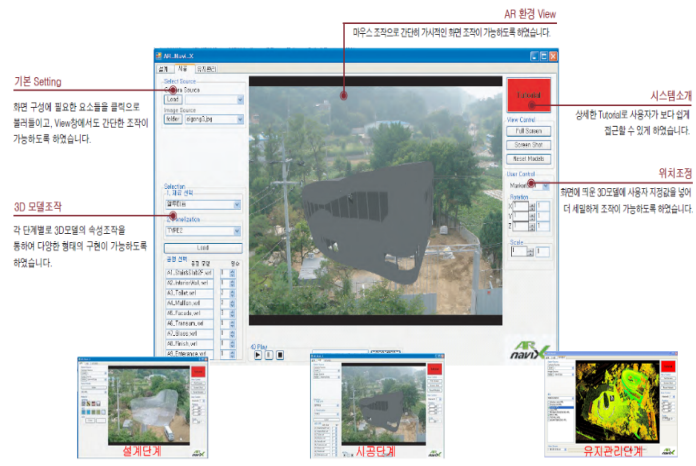

[그림 16] 통합인터페이스 구축

\section{5. 시스템 검증을 위한 워크샵}

개발된 시뮬레이션 시스템이 개발 목표에 얼마나 부합 하는 지, 개선이 필요한 사항은 무엇인지를 판단하기 위 해서는 적절한 시스템 평가가 필요하다. 일반적으로 개 발된 시스템의 평가는 효과성평가, 사용성평가, 효율성평 가를 포함한다.

효과성평가는 시스템이 개발목표를 달성하였는가를 평가하는 것으로 시스템 개발자에 의해 정의된 시스템 활용 기대효과를 사용자가 어떻게 인지하는가를 파악하 는 것을 말하며 사용성 평가는 시스템 사용과정에서 사 용자가 느끼는 편의성 및 실용성과 관련된 평가를 의미 하고 효율성 평가는 시스템 활용으로 얼마나 업무의 효 율이 향상되었는가를 평가하는 것을 말한다.[17]

본 연구는 위 3 가지 평가분야 중 시스템의 효과성과 사용성을 평가하기 위하여 수도권 소재 $\mathrm{S}$ 대학교 건설관 리공학 프로그램 소속 석 - 박사과정 대학원생 24인을 대 상으로 워크샵을 실시하였다. 본 연구에서 개발된 $\mathrm{AR}$ naviX는 설계단계, 시공단계, 유지관리단계의 가상건설 정보와 현실정보를 연계하여 각 단계에서 건설관리자가 필요로 하는 의사결정을 효율적으로 지원하기 위한 시스 템으로, 잠재적인 시스템 사용자를 워크샵 대상으로 설정 하였다. 워크샵 참여자는 증강현실, $\mathrm{BIM}$, 의사결정지원 시스템의 기본적인 지식체계를 모두 이해하고 있으며 참 여자 중 8 인은 설계사무소를 운영하고 6 인은 건설기업 및 건설사업관리용역기업 임직원으로 근무하고 있다.

워크샵의 진행은 참여자에게 $\mathrm{AR}$ naviX 시스템을 설 명한 후 시스템을 사용하는 체험시간을 부여하였으며 시 스템의 효과성을 판단하기 위해 표 2와 같이 시스템 개 발목표와 관련된 2 개의 질문을 도출하였다. 워크샵 참가 자들은 체험시간 경과 후 시스템의 개발목표 대비 효과 성에 대한 인식정도를 1 에서 10 까지의 10 점 척도로 평가 하였다.

[표 2] AR naviX 효과성 평가 질문내용

\begin{tabular}{|c|c|}
\hline \multirow{2}{*}{ 평가항목 } & 기대효과/인지효과 \\
\hline & 매우 그렇다 아니다. \\
\hline $\begin{array}{l}\text { 1. 프로젝트의 각 단계별 } \\
\text { 참여자간 실시간 정보 } \\
\text { 공유가 개선된다. }\end{array}$ & 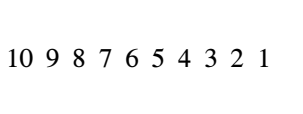 \\
\hline $\begin{array}{l}\text { 2. 변화하는 현장여건에 } \\
\text { 따라 관리 및 계획수 } \\
\text { 립이 개선된다. }\end{array}$ & $1098776 \begin{array}{lllll}10 & 9 & 3 & 2 & 1\end{array}$ \\
\hline
\end{tabular}


표 3은 시스템의 사용성을 평가하기 위해 워크샵 참여 자에게 제공된 질문내용이다. 효과성 평가와 사용성 평가 결과 다음과 같은 결과를 얻었다.

(1) 효과성 측면에서는 워크샵 참여자 24 명 중 1 번 질 문에 대해 240점 만점을 기준으로 총점 181점, 평 균 7.5점으로 프로젝트 참여자 간에 원활한 정보공 유가 개선될 수 있는 것으로 인식하고 있었다. 2 번 질문에 대해서는 총점 174점 (240점 만점)을 얻 어 평균 7.25점으로 변하는 현장여건을 반영한 관 리 및 계획수립이 대체로 개선될 수 있는 것으로 인식하고 있었다.

[표 3] AR naviX 사용성 평가 질문내용

\begin{tabular}{|l|l|l|}
\hline \multirow{2}{*}{ 평가항목 } & 기대효과/인지효과 \\
\cline { 2 - 4 } & 매우 그렇다 아니다. \\
\hline $\begin{array}{l}\text { 1. 시스템 인터페이스: } \\
\text { 데이터 입력, 출력 형 } \\
\text { 식이 적합한가? }\end{array}$ & 109876654321 \\
\hline $\begin{array}{l}\text { 2. 시스템 인터페이스: } \\
\text { 단계별 시스템으로의 } \\
\text { 연결성이 좋은가? }\end{array}$ & 109876554321 \\
\hline $\begin{array}{l}\text { 3. 설계단계 : 매스모델의 } \\
\text { 화면출력 형식은 적합 } \\
\text { 한가? }\end{array}$ & 109876554321 \\
\hline $\begin{array}{l}\text { 4. 시공단계 : } 4 \mathrm{D} \text { 시뮬레 } \\
\text { 이션 모델의 가시성은 } \\
\text { 적합한가? }\end{array}$ & 10987654321 \\
\hline $\begin{array}{l}\text { 5. 유지관리단계 : 다양한 } \\
\text { 각도에서 화면 출력이 } \\
\text { 가능한가? }\end{array}$ & 10987654321 \\
\hline
\end{tabular}

(2) 사용성 측면에서는 워크샵 참여자 24 명 중 1 번과 2번 질문의 득점이 평균 7.3점, 7.8점으로 시스템 인터페이스의 사용성이 높은 편으로 분석되었다. 각 시스템별 요구기능에 따른 사용성 질문 $(3,4,5$ 번)에는 설계단계 평점 7.8점, 시공단계 평점 6.5 점, 유지관리단계 평점 7.2점의 평균점수를 얻었다.

사용성에서 가장 낮은 점수를 획득한 시공단계의 경우 평가자들의 평가이유를 설문한 결과, "4D 시뮬레이션 기 능의 단순성”을 가장 큰 이유로 꼽았고, “구체적 간섭부 위의 확인이 곤란함"이 그 뒤를 이었다.

\section{6. 결론 및 향후 연구}

본 연구에서는 기존의 가상현실 환경에서 구현되는 $\mathrm{BIM}$ 의사결정 지원 시뮬레이션의 한계를 극복한 증강현 실 기반의 새로운 시뮬레이션 $\mathrm{AR}$ naviX를 개발하였다. $\mathrm{AR}$ naviX는 건설 프로세스를 설계단계, 시공단계, 유지 관리단계로 구분하여 각 단계별 참여자들의 건설관리업 무를 지원한다. 먼저 설계단계에서는 대지의 최적매스모 델 결정을 위해 재질입력 및 배치 기능을 구성하고, 시공 단계에서 공정관리 및 간섭체크를 위해 Panelization 및 공정계획을 기반으로 한 $4 \mathrm{D}$ play기능을 구성하였다. 마 지막으로 유지관리단계의 건물용도변경 혹은 조경변경계 획을 지원하기 위해 배관설비, 인테리어, 조경으로 된 3 가지 모델그룹을 지원하여 동영상 플레이어로 시뮬레이 션 할 수 있는 기능을 구성하였다.

건설관리공학 전문가 집단의 워크샵을 수행하여 기존 가상현실 기반의 시뮬레이션 시스템이 가지고 있던 실시 간 정보공유 곤란 및 신속한 의사결정지연 등의 문제가 개선될 수 있는 것으로 인식함을 확인할 수 있었다. 그리 고 워크샵 결과를 바탕으로 향후 연구와 시스템 개선 방 향을 설정하였다.

향후 연구에서는 시공단계 시스템의 공정관리 프로그 램과의 연계방안 또는 시스템 내의 개선된 공정관리 기 능이 추가되어야 할 것이며, 정확한 간섭검토 부위의 추 적이 가능하도록 개선되어야 할 것으로 보인다. 또한 각 단계별 요구기능의 추가와 다양한 프로젝트에서의 적용 을 통한 개선으로 고차원적인 통합시뮬레이션으로의 발 전이 요구된다.

\section{참고문헌}

[1] 이경하 외 4 인, "BIM 기반 건축시공 시뮬레이션 개 발에 관한 연구", 대한건축학회 논문집 계획계, 제 25 권 제5호(통권247호),pp. 763-767, 2009. 05

[2] 홍동표 외 1 인, "모바일 증강 현실 시스템에 대한 연 구 동향", 정보과학회지, 제26권 제1호, pp. 88-97, 2008. 01

[3] 박소영 외 1 인, "기존 건축물의 효율적인 정보 관리 를 위한 증강현실 기술 응용에 관한 연구", 대한건축 학회 논문집 계획계, 제 21 권 제 8 호(통권202호), pp. 37-44, 2005. 08

[4] 임줌폰 외 2 인, "모바일 증강현실 기술을 이용한 건 설관리 시스템, 대한건축학회 논문집 구조계", 제22권 제2호(통권208호), pp. 139-145, 2006. 02 
[5] 정성수 외 2인, "증강현실을 이용한 건물 모니터링 기법 개발", 한국건설관리학회 논문집 제 10 권 제 6 호, pp. 3-12, 2009. 11

[6] Wang, X and Chen, R. "Approaches to Augmenting Virtual Design Environments with Reality," Mixed Reality in Architecture, Design and Construction, Springer Science + Business Media B. V. pp. 15-26, 2009.

[7] Choi, J.W. "A Technological Review 새 Develop an AR-Based Design Supporting System," Mixed Reality in Architecture, Design and Construction, Springer Science + Business Media B. V. pp. 53-74, 2009.

[8] Kaga, A. "Simulation of an Historical Building using a Tablet Mixed Reality System," Mixed Reality in Architecture, Design and Construction, Springer Science + Business Media B. V. pp. 119-134, 2009.

[9] Dunston, P. and Shin, D. "Key Areas and Issues for Augmented Reality Applications on Construction Sites," Mixed Reality in Architecture, Design and Construction, Springer Science + Business Media B. V. pp. 157-170, 2009.

[10] Kvan, T. "Debating Opportunities: Learning Design through Different Structures," Mixed Reality in Architecture, Design and Construction, Springer Science + Business Media B. V. pp. 205-227, 2009.

[11] 정도영 외 1 인, "BIM기반 비용-알정 통합관리 방안 에 관한 연구", 한국건설관리학회 학술발표대회 논문 집, pp. 325-329, 2008. 11

[12] 김지원, "사례분석을 통한 3D 상용 어플리케이션 기 반 BIM데이터의 상호연동성 개선방향에 관한 연구", 한국 $\mathrm{CAD} / \mathrm{CAM}$ 학회 논문집, 제 14 권 제 6 호, $\mathrm{pp}$. 390-403, 2009. 12

[13] 서종철 외 1 인, "국내 건설 공공발주에서 $\mathrm{BIM}$ 도입 및 적용을 위한 기본방향에 관한 연구", 대한건축학 회 논문집 계획계, 제 25권 제 9호, pp. 21-29, 2009. 09

[14] 김인한 외 1 인, "개방형 $\mathrm{BIM}$ 지침 개발에 관한 국 외의 지침 분석 및 전략적 방향에 관한 연구", 한국 건설관리학회 논문집, 제 10 권 제 4호, pp. 58-65, 2009. 07

[15] 안승준 외 2인, "3D Building Information Model을 이용한 공정-비용 통합 시뮬레이터 개발 연구", 한국 정밀공학회 추계학술대회, 제 28권 제 1호, 2008. 10

[16] Morton, S. "A Framework for Development of Decision Support System", MIS Quaretly, Vol. 4, No. 5, 1980, 12.

[17] 이현수 외 4인. 건설회사의 PMIS 평가 및 발전전략 체계연구, 한국선설산업연구원, pp. 65-72, 2005.

\section{안 지 연(Ji-Yena An)}

[준회원]

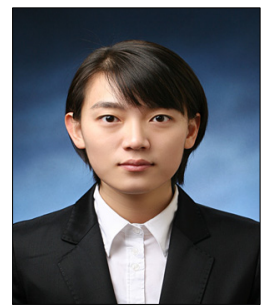

- 2009년 8월 현재 : 서울산업 대학교 산업대학원 건축·토목협 동과정 석사과정

<관심분야>

건설관리, 공정관리, 증강현실, $\mathrm{BIM}$

\section{최 정 민(Jeong-Min Choi)}

[준회원]

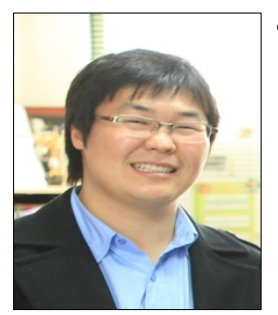

- 2008년 8월 현재 : 서울산업 대학교 산업대학원 건축·토목협 동과정 석사과정

<관심분야>

건설관리, 건설경영, 비정형 외장생산

\section{권 순 호(Soon-Ho Kwon)}

[준회원]

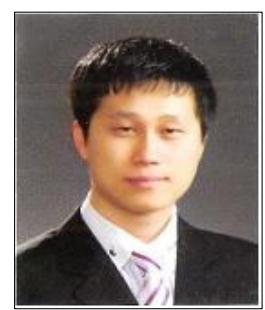

- 2009년 3월 현재 : 서울산업 대학교 산업대학원 건축공학과 석사과정

<관심분야>

건설관리, BIM, 비정형 모델링 기법 
송 두 형(Doo-hyung Song)

[정회원]

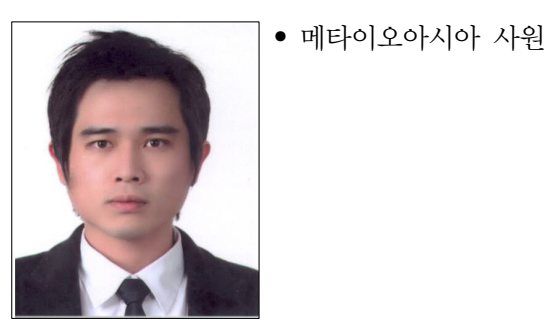

<관심분야>

증강현실, BIM

옥 종 호(Jong-Ho Ock)

[정회원]

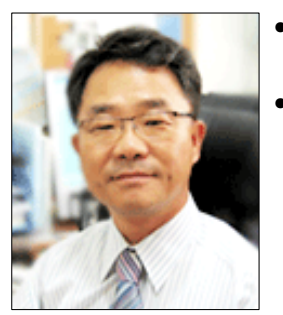

- 1998년 5월 : Univ. of Boulder. USA 건설관리공학(공학박사)

- 2004년 10월 현재 : 서울산업 대학교 건축학부 조교수

<관심분야>

건설관리, 건설경영, 증강현실, $\mathrm{BIM}$ 